\title{
DESEMPREGO E SUBJETIVIDADE: ESTRATÉGIAS DE INCLUSÃO SOCIAL E SOBREVIVÊNCIA ${ }^{1}$
}

\author{
Adriana Cristina Ferreira Caldana ${ }^{2}$ \\ Marco Antonio de Castro Figueiredo \\ FFCLRP - Universidade de São Paulo
}

\begin{abstract}
RESUMO: O desemprego estrutural pode ser apontado como um dos principais fenômenos da fase atual do capitalismo. O objetivo deste estudo foi levantar algumas categorias associadas ao desemprego $\mathrm{e}$ analisar estratégias adotadas por indivíduos frente a essa situação. Para tanto, foram realizados estudos de casos com vinte sujeitos desempregados, de ambos os sexos, com idade entre 30 e 45 anos e candidatos às vagas oferecidas pelo Sistema Nacional de Empregos (SINE) em Ribeirão Preto. Os resultados mostraram estratégias predominantemente individualizadas para o enfrentamento da situação de desemprego, marcadas pela busca de emprego junto às agências especializadas, aliada à realização de trabalhos precários. Os resultados indicam a necessidade de procurar formas de suporte à população estudada e que considerem questões afetivas associadas ao fenômeno do desemprego, privilegiando ações coletivas às individualizadas.
\end{abstract}

Palavras-chave: Desemprego, saúde mental, trabalho.

\section{UNEMPLOYMENT AND SUBJECTIVITY: ESTRATEGIES OF SOCIAL INCLUSION AND SURVIVAL}

\begin{abstract}
The structural unemployment is a current phenomenon of the capitalism. The aim of this study was to investigate which are the major effects of the unemployment. A total of 20 study cases were developed with unemployed people; all of them were applying for jobs offered by the National Employment System in Ribeirão Preto (Brazil). Both genders and ages ranging from 35 to 45 years old were accepted for the positions. The results showed some strategies (predominantly individualized) used when facing unemployment situations. These strategies were characterized by the realization of precarious work and search for jobs in specialized organizations. Our results pointed out the necessity of searching new forms of supporting the studied population, considering affective features associated to the unemployment phenomenon and favoring shared actions and not individualized ones.
\end{abstract}

Key-words: Unemployment, mental health, work

A atual fase de reestruturação produtiva do capital, com seus processos de acumulação flexível, desemprega ou precariza praticamente um bilhão de pessoas, o equivalente a um terço da força de trabalho mundial (Antunes, 1999).

A questão da centralidade do trabalho na sociedade contemporânea é tema controverso.

\footnotetext{
Artigo recebido para publicação em março de 2002, aceito em junho de 2002.

2 Endereço para correspondência: Adriana Cristina Ferreira Caldana, Programa de Pós-Graduação em Psicologia. Faculdade de Filosofia Ciências e Letras de Ribeirão Preto-USP, Av. Bandeirantes, 3900, Monte Alegre, Ribeirão Preto, SP, Cep 14040-901, e-mail adrianacaldana@hotmail.com
}

Entretanto, não se pode anunciar uma crise e/ou o fim do trabalho, talvez seja possivel apenas sugerir o fim do trabalho sob a forma de emprego formal. Com o desemprego estrutural observamos a diminuição do proletariado industrial e o aumento constante da subproletarização, verificada pela expansão de outras formas de organização do trabalho: terceirizações, trabalhos em tempo parcial, subcontratações, temporários, etc. (Antunes, 1995).

O downsizing, diminuição dos níveis hierárquicos da empresa, com enxugamento da estrutura organizacional e conseqüente diminuição do número de funcionários, foi um dos principais 
fenômenos registrados nas organizações nos últimos anos (Boog, 1991). O principal expoente dessa tendência é o modelo japonês da Toyota, que se disseminou rapidamente, em diversas nuanças, pelo mundo industrializado, como: Suécia, Itália, Alemanha, EUA (Antunes, 1999; Hirata, 1993).

A toyotização do ocidente impôs sacrifícios aos trabalhadores, pois os processos de terceirização, além de reduzirem os quadros de funcionários das empresas, geram maior precarização do trabalho. Segundo Antunes (1999),

"Quanto mais o trabalho se distancia das empresas principais, maior tende a ser a sua precarização. Por isso os trabalhadores da Toyota trabalham cerca de 2.300 horas por ano enquanto os trabalhadores das empresas subcontratadas chegam a trabalhar 2.800 horas". (p.57)

A complexidade do fenômeno do desemprego tem gerado diversas definições que englobem os diferentes tipos de desemprego. No Brasil, o DIEESE (Departamento Intersindical de Estatística e Estudos Sócio-Econômicos), um dos órgãos que realiza a Pesquisa de Emprego e Desemprego (PED), considera o desemprego tctal como a somatória do desemprego aberto (caracterizado pelas pessoas que procuram trabalho e não realizam nenhuma atividade remunerada), com o desemprego oculto pelo trabalho precário (pessoas que realizam algum tipo de atividade descontínua e irregular enquanto estão à procura de trabalho), mais o desemprego ocuito pelo desalento (pessoas que, desencorajadas pelas condições do mercado de trabalho ou por razões circunstanciais, interromperam a procura, embora ainda queiram trabalhar). Levantamentos realizados pelo DIEESE (2000) mostram que o desemprego total, na região metropoiitana de São Paulo, saltou de 8.7\% em 1989, para 19,3\% em 1999, ou seja, o número de desempregados na Grande São Paulo quase triplicou durante a década de 1990 , passando de $614 \mathrm{mil}$ pessoas em 1989 para 1,715 milhão em 1999.

Pochmann (1998) amplia ainda mais esse contexto, diferenciando o desemprego em outros 4 tipos: a) Desemprego de Inserção - que atinge a população com menos de 25 anos de idade e que está procurando o seu primeiro emprego; b)Desemprego Repetitivo: marcado por uma redução dos níveis de emprego no Brasil entre 1989 e 1998, fazendo com que jovens com menos de 25 anos de idade não consigam mais se fixar no posto de trabalho a médio e longo prazo; c) Desemprego de Reestruturação: em geral, atinge trabalhadores entre 25 e 50 anos de idade e que trabalham em setores econômicos que estão se reestruturando; $d$ ) Desemprego de Exclusão: atinge pessoas com mais de 50 anos, que encontram cada vez mais dificuldade para voltar ao mercado de trabalho.

Para este autor, a crise do emprego enfrentada hoje se deve ao fato de que o Brasil, entre 1890 e 1980, foi a economia que mais cresceu no mundo sem ter resolvido questões básicas do mercado de trabalho: Reforma Agrária, Reforma Tributária e Reforma Social. Um segundo determinante, seria o baixo crescimento econômico do país de 1980 para cá. Outra explicação seria a mudança de modelo econômico - o país abandonou um projeto de industrialização nacional e partiu para um "modelo de inserção internacional competitiva". A quarta e úitima causa da situação, diz respeito às medidas do governo atual para o desemprego; segundo Pochmann (1999), tais medidas não são ativas e são baseadas apenas na flexibilização dos contratos e na desregulamentação do mercado de trabalho.

\section{Subjetividade e Trabalho}

Para Karl Marx (Braverman, 1987), a essência do ser humano está no trabalho e o indivíduo equivale àquilo que produz e ao modo como produz. Diante de tal colocação, é possível uma breve reflexão sobre a natureza do trabalho humano. Vários autores escreveram sobre a importância da consciência do homem no seu processo de trabalho e do vínculo entre produtor e produto (Antunes, 1999; Braverman, 1987; Wright-Mills, 1969). No trabalho humano está, ou deveria estar, algo que não podemos encontrar em nenhuma atividade animal: a consciência e a intencionalidade:

Estudos no campo da Saúde Mental no. Trabalho apontam para a alienação como fator determinante do que é correntemente chamado de 
desgaste mental do trabalhador (Camon-Angerami, 1986; Seligman-Silva, 1994).

Neste contexto, Seligman-Silva (op, cit.) identifica as relações reificadas no processo de organizações do trabalho, alienadas e fetichizadas, onde o trabalho dominado, cindido entre execução e concepção atua sobre a subjetividade do trabalhador.

Segundo Antunes (1999) a apropriação do savoir faire intelectual e cognitivo do trabalho, as vezes, sob a falácia da Qualidade Total, permite a construção de uma subjetividade não autêntica; a cisão entre o mundo intelectivo e a realidade social leva os indivíduos a assumirem necessidades individuais, perdendo-se a origem de um processo que se fundamenta na reificação. E nesse mundo fetichizado o homem é fonte de erro, e os trabalhadores sentem a pressão de se manterem dentro do contingente ativo de força de trabalho.

A condição para essa manutenção é o contínuo aperfeiçoamento, dentro de uma perspectiva de aptidão, determinada por um conhecimento já anteriormente definido, conforme dito por Antunes (1999):

"Mais complexificada, a aparência de maior liberdade no espaço produtivo tem como contrapartida o fato de que as personificações do trabalho devem se converter ainda mais em personificaçôes do capital. Se assim não o fizerem, se não demonstrarem essas "aptidões" ("vontade", "disposição" e "desejo"), trabalhadores serão substituídos por outros que demonstrem "perfil" $e$ "atributos" para aceitar esses "novos desafios". (p.130)

Nesse contexto, o trabalho simplificado é destituído do seu caráter histórico e se transforma em atividade; $o$ indivíduo não se identifica com o que realiza, o desgaste da identidade leva ao sofrimento psíquico e coloca a saúde menfal dentro de uma perspectiva de saúde coletiva, determinada pelo distanciamento entre o trabalho e seu sujeito. Essa perda de identidade com o trabalho pode gerar distúrbios psicossomáticos, alcoolismo, entre outros transtornos (Seligman-Silva, 1994).
A discussão sobre a situação daqueles que estão inseridos nas organizações atuais (empregados), nos permite enxergar de maneira mais contextualizada a situação dos que estão sendo "excluídos": os desempregados.

O desemprego estrutural, provocado pelas transformações econômicas da atual fase de reestruturação produtiva do capital, agrava ainda mais esse quadro, pois faz com que os trabalhadores vivam ainda sob o fantasma constante dos cortes de pessoal das empresas, o que aumenta a tensão dos mesmos, e serve para os empregadores como instrumento de pressão e de intensificação da exploração (CamonAngerami, 1986).

O caminho percorrido por aqueles que são demitidos costuma passar pelas longas filas das agências de empregos. Estes trabalhadores enfrentam uma situação crítica em busca de algo que vem se tornando cada vez mais escasso: o trabalho sob a forma de emprego.

Ao construir estratégias de sobrevivência e de recolocação no mercado de trabalho os indivíduos atravessam um processo de desvalorização (Oliveira, Sato \& Mazzio, 1998). O desemprego gera desqualificação que por sua vez estigmatiza e culpabiliza: ao perder o emprego o trabalhador é marcado com o sinal da incompetência. A crença atual no conceito de auto-desenvolvimento facilita a estigmatização (Goffmann, 1988) dessas pessoas, pois elas são vistas como aquelas que fracassaram em se qualificar e se tornar competitivas e, portanto, culpadas por não serem empregáveis, o que pode dificultar ainda mais a reinserção destes trabalhadores no mercado de trabalho.

\section{Objetivos}

$\mathrm{Na}$ pesquisa realizada entre 1998 e 2000 , buscou-se levantar as representações que os indivíduos em procura de emprego possuem acerca do desemprego e as estratégias de sobrevivência e inclusão no mundo produtivo adotadas por eles.

$O$ estudo foi realizado em duas fases. A primeira fase teve como objetivo promover um primeiro contato com a realidade a ser investigada, abordando três aspectos:

- Histórico Profissional: levantamento da 


\section{Adriana Cristina Ferreira Caldana}

experiência profissional do indivíduo;

- Concepção do Trabalho: levantamento das representações dos sujeitos quanto ao significado atribuído ao ato de trabalhar, antes e após a saída do emprego;

- Aspectos Concretos: investigação de transformações que poderiam ter ocorrido na rotina de vida desses sujeitos com a saída do emprego;

$\mathrm{Na}$ segunda fase, investigaram-se as principais estratégias de sobrevivência e inclusão no mundo produtivo adotadas por indivíduos em busca de emprego.

\section{Método}

Foi realizado um estudo preliminar junto a uma amostra de dez usuários do "Balcão de Empregos" do Sistema Nacional de Empregos (SINE) no posto de Ribeirão Preto. Os sujeitos tinham entre 35 e 45 anos; estiveram empregados pelo menos 5 anos numa mesma organização (independente do ramo de atuação); e estavam desempregados há, no máximo, 6 meses.

Este estudo exploratório foi realizado através de entrevistas semi-estruturadas que eram gravadas e transcritas na íntegra e posteriormente analisadas de acordo com o seguinte procedimento:

a) Leitura inicial: Foi realizada uma primeira leitura dos 10 textos transcritos para que se pudesse ter um panorama geral das entrevistas, identificando os trechos mais importantes de cada uma delas.

b) Marcação: Foram selecionados, em cada entrevista, os trechos que possuíam conteúdos similares aos das demais entrevistas.

c) Corte: Os trechos selecionados foram retirados dos textos. d) Junção: Os trechos mais representativos das 10 entrevistas foram agrupados $e$ categorizados.

e) Categorização: Todos os agrupamentos foram revjstos, possibilitando a construção de 20 categorias referentes aos enunciados selecionados.

f) Avaliação das categorias: A análise das entrevistas piloto levou à construção de um protocolo, contendo as 20 categorias identificadas nas entrevistas e 75 enunciados dos entrevistados. Este protocolo foi submetido à avaliação de três juízes neutros, com nível universitário, que relacionavam as categorias listadas com os enunciados. Após a análise da concordância entre os 3 juízes (diagrama de Venn), foram construídos nove cartões contendo as categorias convergentes e que apresentaram índice de participação maior que $5 \%$ - índice de pregnância 0.05 . Estes nove cartões eram o ponto de partida para as entrevistas da segunda fase.

$\mathrm{Na}$ fase seguinte da pesquisa, vinte sujeitos, com o mesmo perfil da exploratória, foram entrevistados e submetidos ao questionário de qualidade de vida elaborado pela Organização Mundial de Saúde - WHOQOL-100: World Health Organization Quality of Life - 100 (Fleck, 1999). ${ }^{3}$

Após uma breve entrevista de caracterização dos sujeitos e aplicação do questionário de qualidade de vida, marcava-se uma segunda sessão, a ser realizada na casa dos sujeitos, quando era feita uma entrevista de aprofundamento dos resultados obtidos pelo sujeito no questionário, e das suas representações sobre conteúdos previamente levantados na pesquisa piloto.

A tabela a seguir apresenta os dados demográficos da amostra estudada.

Tabela 1: Caracterização da amostra quanto ao sexo, cor, idade, escolaridade e forma desligamento $(\mathrm{N}=20)$

\begin{tabular}{|c|c|c|c|c|}
\hline SEXO & COR & IDADE & ESCOLARIDADE & DESLIGAMENTO \\
\hline Fem - 50\% & Branco - 55\% & 35 a $39-60 \%$ & Fundamental 60\% & Involuntário - 65\% \\
& Pardo - 25\% & & Média - 35\% & \\
Masc-50\% & Negro-20\% & 40 a 45-40\% & Superior - 5\% & Voluntário-35\% \\
\hline
\end{tabular}

\footnotetext{
${ }^{3}$ Os resultados deste questionário não serão apresentados por não
} fazerem parte dos objetivos da presente análise, 


\section{Resultados}

Estudos de casos, realizados a partir da análise de conteúdo das entrevistas nas duas fases da pesquisa, permitiram a identificação de categorias associadas ao desemprego e de estratégias adotadas para o enfrentamento dessa situação. $\mathrm{O}$ quadro sintetiza essas categorias e estratégias

Quadro 1: Síntese das categorias associadas ao desemprego e das estratégias adotadas.

\begin{tabular}{|c|c|}
\hline $\begin{array}{l}\text { FASE } 1 \text { - LEVANTAMENTO DE CATEGORIAS } \\
\qquad N=10\end{array}$ & $\begin{array}{l}\text { FASE } 2 \text { - LEVANTAMENTO DE ESTRATÉGIAS } \\
\qquad N=20\end{array}$ \\
\hline $\begin{array}{l}\text { 1. Alterações de estados psíquicos: } \\
\text { Modificações em seu estado emocional ou psicológico após a } \\
\text { saída do emprego; } \\
\text { 2. Relacionamentos sociais e familiares: } \\
\text { tratamento de parentes e/ ou amigos após a saída do emprego; } \\
\text { 3. Desligamento involuntário: } \\
\text { a demissão foi iniciativa da empresa; } \\
\text { 4. Desligamento solicitado: } \\
\text { indivíduo pede demissão ou solicita que a empresa o demita; } \\
\text { 5. Contextualização econômica: } \\
\text { relacionar a situação que está vivenciando com questões } \\
\text { políticas, sociais e econômicas mais amplas; } \\
\text { 6. Obstáculos frente à reinserção no mercado de trabalho: } \\
\text { dificuldades encontradas para conseguir um novo emprego; } \\
\text { 7. Saúde fisica e mental: } \\
\text { estado de saúde em que se encontra no momento da entrevista; } \\
\text { 8. Independência financaira: } \\
\text { importância dada ao fato de não depender de outras pessoas para } \\
\text { se manter financeiramente; } \\
\text { 9. Realização pessoal: } \\
\text { papel do trabalho enquanto uma forma de se desenvolver, ou } \\
\text { conseguir satisfação pessoal. }\end{array}$ & $\begin{array}{l}\text { 1. Procura em agências de empregos: } \\
\text { essa estratégia foi enunciada por todos os sujeitos e refere-se a } \\
\text { buscar apoios em instituições especializadas na captação e } \\
\text { divulgação de vagas de emprego ( } p=1.0 \text { ); } \\
\text { 2. Trabalhos precários: } \\
\text { realização de trabalhos com pouca seletividade - "bicos"( } p= \\
\text { 50); } \\
\text { 3. Procura junto às empresas: } \\
\text { visitas diretas às empresas da região ( } p=.50 \text { ); } \\
\text { 4. Renda familiar: } \\
\text { apoio financeiro em outros membros da familia como estratégia } \\
\text { de enfrentamento ( } p=50 \text { ); } \\
\text { 5. Rede de amigos: } \\
\text { contato com amigos em busca de oportunidades de trabalho } \\
\text { ( } p=.20 \text { ); } \\
\text { 6. Migração: } \\
\text { mudaņ̧as de cidades para encontrar trabalho ( } p=.20 \text { ); } \\
\text { 7. Negócio próprio: } \\
\text { abertura de empresa como alternativa à falta de vagas no } \\
\text { mercado de trabalho ( } p=.15 \text { ); } \\
\text { 8. Qualificação: } \\
\text { realização de cursos para atender as demandas do mercado de } \\
\text { trabalho ( }=.15 \text { ); } \\
\text { 9. Sindicatos: } \\
\text { busca de vagas através de contatos com sindicatos da categoria } \\
\text { ( } p=.10 \text { ). }\end{array}$ \\
\hline
\end{tabular}

\section{Discussão}

Analisando as categorias surgidas na primeira fase da pesquisa observou-se que o desemprego interfere na saúde física e mental do trabalhador e seus relacionamentos sociais, o que está de acordo com os resultados dos principais estudos sobre desemprego (Murphy, 1999). Estes dados foram corroborados pelas entrevistas da segunda fase da pesquisa, que também mostraram os sujeitos associando o trabalho a sentimentos de realização pessoal.

Os trabalhadores desempregados apontaram a crise econômica e política do país, bem como alguns critérios de seleção das empresas (idade e escolaridade) como causas da situação que estavam vivenciando. Quanto à origem do desemprego, esses resultados reiteram a complexidade do fenômeno apontada no estudo de Oliveira e Costa (1998), que verificou a contradição presente nos discursos de tra- balhadores (empregados e desempregados) quando estes se referem às causas do desemprego; tais dados, além de indicar a complexidade da questão, indicam a dificuldade de integrar a esfera individual com a macrossocial.

As estratégias utilizadas para o enfrentamento do desemprego se mostraram predominantemente individualizadas e emergenciais, sendo que poucos possuem um projeto para o futuro.

A adoção de alternativas individualizadas parece estar em função da não percepção do poder de decisão, ou então, da reificação da consciência do proletariado que naturaliza o processo (Lukács, 1974), e parece levar os indivíduos a adotarem estratégias individualizadas, não vendo possibilidades de atuarem coletivamente e aguardarem uma mudança na superestrutura (política). Entretanto, na maioria dos casos analisados há a descrença em relação às pessoas que poderiam realizar alguma mudança estrutural 


\section{Adriana Cristina Ferreira Caldana}

(políticos), o que gera insatisfação, impotência e desintegração social, confirmando Ramtin (apud Antunes, 1999):

"Para os permanentemente desempregados e desempregáveis, a realidade da alienação significa não somente a extensão da impotência ao limite, mas uma ainda maior intensificação da desumanização física $e$ espiritual (...) $O$ aspecto vital da alienação deve-se ao fato de que a impotência está baseada na condição da integração social pelo trabalho. Se essa forma de integração social está sendo crescentemente prejudicada pelo avanço tecnológico, então a ordem social começa a dar sinais de instabilidade e crise, levando gradualmente em direção a uma desintegração social geral." (p.132)

Tal desintegração passa a ser um elemento da vida do trabalhador. Segundo Marx (Lukács, 1974) a reificação penetra até a "alma" (p. 103) do trabalhador, e do ponto de vista da auto-estima, auto-realização e enfrentamento das condições impostas pelo capital, o coloca frente às determinações sociais como um elemento contemplativo que se submete a tais condições. As estratégias de inclusão no mundo da produção pela realização de trabalhos precários marcam a naturalização da situação de desemprego.

Metade dos sujeitos do grupo citaram que estava indo diretamente às empresas "fazer ficha" ou deixar currículos, mas julgavam tal ação ineficaz, pois essas ou não davam nenhum retorno ou nem mesmo os recebiam.

Quanto à estratégia renda familiar, a variável gênero apareceu com destaque nos dados, sendo que dentre os dez sujeitos que citaram estar sobrevivendo graças a ela, sete eram mulheres.

O fato de dois dos sujeitos, ambos do sexo masculino e vendedores, adotarem a estratégia de se estabelecerem de forma autônoma como alternativa ao desemprego, corrobora os dados da pesquisa realizada por Oliveira, Sato e Mazzio (1988), que indicam a existência de uma tendência de busca pelo trabalho autônomo nos sujeitos masculinos não operacionais. Nesse estudo, tem-se ainda um outro sujeito, mas do grupo operacional, que também havia adotado essa estratégia, mas já estava pensando em desistir em função do baixo rendimento obtido em sua oficina mecânica.

A busca pelo emprego através de agências não pareceu eficiente nos casos dos sujeitos entrevistados, pois o fato de os critérios de qualificação (experiência profissional e escolaridade) e idade serem os mais utilizados nesse tipo de seleção tem restringido as possibilidades desses indivíduos se recolocarem no mercado de trabalho por essa via.

Em relação à qualificação, observou-se que os escassos recursos financeiros disponíveis impedem que o sujeito continue a investir na qualificação que vem sendo exigida no mercado de trabalho. A esse respeito, Antunes (1999) destaca o aspecto falacioso dessas exigências:

"Isso faz aflorar o sentido falacioso da "qualificação do trabalho", que muito frequientemente assume a forma de manifestação mais ideológica do que uma necessidade efetiva do processo de.produção." (nota de rodapé, p. 52).

Alguns dos sujeitos, apesar de julgarem que as exigências das empresas por qualificação sejam "descabidas", permanecem acreditando na importância de se qualificarem, para continuarem competitivos no mercado de trabalho. Dessa forma, o desemprego gera desqualificação, já que os indivíduos fora das empresas deixam de ter acesso aos recursos necessários para continuarem investindo na formação exigida, e, assim, se tornam cada vez menos competitivos no mercado de trabalho. Note-se que os sujeitos 2 e 6 vão buscar os cursos gratuitos oferecidos pelo governo e por sindicatos.

Geralmente, para as sub-populações com as características dessa amostra, as oportunidades de qualificação surgem de iniciativas públicas ou de determinadas entidades. Pochmann (1999) cita a falta de investimentos das empresas na formação profissional:

"Além do sistema "S", que opera com recursos parafiscais (contribuição sobre o custo de contratação do empregado), as 
escolas técnicas (federais, estaduais e municipais) são financiadas com recursos públicos. De certa forma, os empresários brasileiros não possuem experiência na qualificação de seus empregados." (p. 123)

O desejo de que os empresários invistam na qualificação dos empregados está presente na proposta do sujeito 15 , que diz respeito, principalmente, à responsabilidade social das empresas em relação à educação de seus funcionários. Segundo a visão desse sujeito, um maior investimento das empresas em cursos profissionalizantes, geraria desenvolvimento dos trabalhadores:

\begin{abstract}
"Agora, se vocês deveria fazê uma carga menos de trabalho, fazê um, um, tipo assim, como é que fala? E... um curso técnico em cima daquele trabalho, prá você crescê e você estudá à noite. Eu acho que isso ajudaria muito... as empresas poderiam oferecê isso... Quer dizê, eles teriam aqueles funcionários sempre crescendo, que eu ouvi um homem falá que ein São Paulo, a Wolks, né? E outras empresas maior, lá, eles, funcionário, a pessoa lá trabalha e estudam, e tão sempre crescendo com cursos e outras coisas mais que tem lá." (sujeito 15: doméstica, 39 anos, ensino fundamental incompieto)
\end{abstract}

A questão da idade também apareceu como fator que restringe o acesso a oportunidades de trabalho. Realmente, cada vez mais as empresas parecem estar em busca de "jovens talentos". Isso leva a questionar a verdadeira razão dessa preferência; seria o indivíduo mais jovem realmente mais "capaz"ou mais submisso à crescente exploração do capitalismo atual. Pollert (Antunes, 1999) realizou pesquisas que indicaram que:

"somente um grupo minoritário, composto de jovens, realmente gosta da introdução das 'novas técnicas', enquanto que a maioria se considera sobrecarregada de trabalho e insatisfeita." (p.88)
Frente a essas constatações, coloca-se a abertura de espaços públicos para a discussão da problemática do desemprego como uma possibilidade de suporte a essa população. Estes espaços favoreceriam modos de atuação menos individualizados, permitindo a ressignificação da experiência do desemprego, dentro de uma perspectiva em que o "indivíduo" possa se enxergar como "sujeito".

\section{Referências Bibliográficas}

Antunes, R. (1995). Adeus ao trabalho? Ensaio sobre as metamorfoses $e$ a centralidade do mundo do trabalho. 2.ed. Campinas: Cortez Editora da UNICAMP.

Antunes, R. (1999). Os sentidos do trabalho: ensaio sobre a afirmação e a negação do trabalho. São Paulo: Boitempo Editorial.

Braverman, H. (1987). Trabalho e capital monopolista: a degradação do trabalho no século XX. 3. ed. Rio de Janeiro: Guanabara.

Boog, G. G. (1991). O desafio da competência. São Pauio: Best Seller.

Camon-Angerami, V.A. (Org.) (1986), Crise, Trabalho e Saúde Mental no Brasil. São Paulo: Traço.

DIEESE: Departamento Intersindical de Estatística e Estudos Sócio-Econômicos PED-Pesquisa de Emprego Desemprego [on line] www.dieese.org.br, 17/08/2000.

Fleck, M. P. A., Leal, O. F., Louzada, S., Xavier, M., Chachamovich, E., Vieira, G. Santos, L. \& Pinzon, V. (1999). Desenvolvimento da versão em português do instrumento da avaliação de qualidade de vida da OMS (WHOQOL-100). Revista Brasileira de Psiquiatria, 21 (1), 19-28.

Goffman, E. (1988). Estigma: Notas sobre a manipulação da identidade deteriorad.4.ed. Rio de Janeiro: Guanabara.

Graetz, B. (1993). Health consequences of employment and unemployment: longitudinal evidence for young men and women. Social 
26 Adriana Cristina Ferreira Caldana

Science and Medicine, 36 (6), 715-724.

Hirata, H. (1993). Sobre o "Modelo" Japonês: Automatização, Novas Formas de Organização e de Relações de Trabalho. São Paulo: Edusp.

Hirata, H. \& Humphrey, J. (1992). Estruturas familiares e sistema produtivo: famílias operárias na crise. Tempo Social: Revista de Sociologia da USP, 4(1): 111-131

Kupers, T. A. (1996). Men at work and out of work. Psychiatric-Annals, 26 (1), 29-32.

Ianni, Octavio (1992). Karl Marx. 7. ed. Coleção Grandes Cientistas Sociais. São Paulo: Ática.

Lukács, G. (1974). A reificação e a consciência do proletariado. Em G. Lukács (org.), História e consciência de classe (pp. 97-231). Porto: Publicações Escorpião.

Murphy, G.C. \& Athanasou, J.A. (1999). The effect of unemployment on mental health. Journal of Occupational and Organizational Psychology, 72, 83-99.

Oliveira, F. \& Costa, M. S. (1998). Desemprego e ideologia: as explicações das causas do desemprego utilizadas por trabalhadores metalúrgicos. Cadernos de Psicologia Social e do Trabalho, 1 (1), 1-13.

Oliveira, F., Sato L. \& Mazzio, S. A. (1998). As estratégias de sobrevivência e de busca de emprego adotadas pelos desempregados. Cadernos de Psicologia Social e do Trabalho, 1 (1) 1542.

Pochmann, M. A (1998). Globalização e a Tendência do Emprego no Brasil nos Anos 90. Revista do Seminário Geração de Emprego e Renda. São Paulo: Gabinete do vereador Carlos Neder.

Pochmann, M. (1999). O Trabalho sob Fogo Cruzado. São Paulo: Contexto.

Seligman-Silva, E. (1994). Desgaste mental no trabalho dominado. Rio de Janeiro: UFRJ-Cortez.

Vinamaki, H.; Koskela, K. \& Niskanen, L. (1993). The impact of unemployment on psychosomatic symptoms and mental well-being. International
Journal of Social Psychiatry, 39 (4), 266-273.

Viinamaki, H.; Koskela, K.; Niskanen, L.; Arnkil, R. \& Tikkanen J. (1993). Unemployment and mental wellbeing: a factory closure study in Finland. Acta Psychiatry Scand, 88 (6), 429-433.

Vinokur, A. D.; Price, R.H. \& Schul, Y. (1995). Impact of the jobs intervention on unemployed works varying in risk for depression. American Journal of Community Psycology, 23 (1), 3974.

Wright-Mills, C. (1969). O trabalho. Em C. WrigtMills (org.), A Nova Classe Média (pp. 233256). Rio de Janeiro: Zahar. 